\title{
Resúmenes de la Literatura Actual
}

\section{CARCINOMA DE ENDOMETRIO - TRATAMIENTOS - RESULTADOS}

SLOT, E., \& UHER, U. (J. E. Purkyne Univ.,) BRUO, (Zechoslovakia). Neoplasma. 18: 395-401, 1971.

Se analizan los resultados de 120 pacientes tratados por $\mathrm{Ca}$. de endometrio después de un período de 5 años. Cuatro planes terapéuticos se utilizaron: 1) Radioterapia. 2) Cirugía. 3$)$ Cirugía con radioterapia postoperatoria. 4) Radium preoperatorio seguido de cirugía y radioterapia post-operatoria. En el $70,8 \%$ se obtuvo supervivencia de varios años, sin signos de enfermedad. Comparando las tasas de supervivencia de 5 años en las cuatro diferentes modalidades terapéuticas, se obtuvieron los siguientes resultados:

Tratamiento $1-55,1 \%$ de supervivencia.

$$
\begin{aligned}
& \text { Tratamiento } 2-61,9 \% \text {. } \\
& \text { Tratamiento } 3-87,5 \% \text { y } \\
& \text { Tratamiento } 4-92,3 \% \text {. }
\end{aligned}
$$

Los pacientes (120) se dividieron en tres grupos: Grupo A: 68 pacientes con estado I y en varios la operación se consideró posible. Grupo B: 44 pacientes con estado I y en quienes la operación se consideró de alto riesgo. Grupo C: 8 pacientes con estado II 80,8\% (55 pacientes) del grupo A sobrevivieron independientemente del tratamiento utilizado; $61,3 \%$ (27 pacientes) del grupo B sobrevivieron y $37,5 \%$ ( 3 pacientes) del grupo C sobrevivieron.

La diferenciación morfológica del tumor, así como el número de cromosomas en la línea basal del tumor fueron de importancia para los resultados del tratamiento.

Los resultados terapéuticos dependieron significativamente de la profundidad de la infiltración del tumor en el miometrio.

\section{INFARTO DEL MIOCARDIO DURANTE EL EMBARAZO: REPORTE DE DOS CASOS CON REVISION DE LA LITERATURA}

HUSAINI, MH. (Newcastle General Hospital, Newcastle on Tyne, England). Postgrad. Me. J. 47: $660-665,1971$.

Se observaron dos pacientes con infarto del miocardio. Una paciente de 40 años, fue vista desde el cuarto mes de embarazo con hipertensión.
El aumento de la tensión se había reportado en dos embarazos anteriores, retornando a lo normal después de cada parto. El diagnóstico de in- 
farto agudo del miocardio fue confirmado por ECG y estudios enzimáticos. Inicialmente hubo evidencia de shock. Fenindione (Dindevan) se administró por cuatro meses, con recuperación inicial pero en el séptimo mes de gestación se presentó falla cardíaca con escasa respuesta a la terapéutica. Cerca del término se obtuvo un niño vivo por cesárea, con rápida recuperación de la insuficiencia cardíaca y de la hipertensión. Una semana más tarde se presentó trombosis de la pierna requiriendo terapéutica con anticoagulantes.

La segunda paciente, de 32 años, fue vista en el noveno mes de embarazo; tenía una historia previa de depresión y había recibido diazepam. El diagnóstico de infarto cardíaco inferolateral fue confirmado por ECG. No se presentaron complicaciones; tuvo un parto normal espontáneo con niño vivo a término. No se presentó evidencia de descompensación cardíaca en esta paciente pero persistieron dolores anginosos atípicos.
Se han reportado 33 pacientes con infarto del miocardio durante el embarazo. 11 de 13 muertes ocurrieron en aquellas pacientes en las cuales el infarto se desarrolló durante el último mes de gestación o durante el trabajo. El promedio de mortalidad fue de $28 \%$ y se distribuyó igualmente entre pacientes normotensas y pacientes hipertensas. Todas las 12 pacientes a las cuales se les suministró terapéutica anticoagulante sobrevivieron a su embarazo; un feto murió. La intervención cesárea se practicó en pacientes con angina, insuficiencia cardíaca, o shock, sintomatología importante.

La terminación del embarazo se justifica en tales pacientes. La operación cesárea no se asoció con mortalidad en las 11 pacientes en las cuales se practicó. Las pacientes que se recuperaron satisfactoriamente del episodio agudo, tuvieron su parto con o sin necesidad de cesárea.

\title{
CONTRACEPTIVOS ORALES DESPUES DE ENFERMEDAD HEPATICA
}

\author{
EISAlO, A., KONTtineN, A., \& HIETAlA, O. Brit. Med. J. 3: 561-562, 1971
}

Usualmente se dice que en las enfermedades hepáticas es más seguro no suministrar contraceptivos orales después de la fase aguda de la enfermedad. Para tratar de establecer con mayor precisión, la influencia de los contraceptivos orales en la función hepática se practicaron tests en mujeres convalecientes de ictericia. Había dos grupos de pacientes, uno de 10 mujeres con edades entre 17 y 43 años después de hepatitis por virus, $y$ otro de cinco mujeres con edades de 17 a 19 años después de ictericia obstructiva.
El diagnóstico de hepatitis viral se basó en el curso clínico y en los hallazgos de laboratorio y fue confirmado por biopsia hepática en 8 pacientes. Seis habian usado contraceptivos orales durante varios meses antes de su admisión al hospital. En el grupo de ictericia obstructiva esta fue causada en dos pacientes por cálculos, en dos por colecistitis y en una por fibrosis del esfínter de Oddi. En cuatro pacientes el diagnóstico se hizo en el momento de la operación. En dos la biopsia hepática mostró moderada colestasis; una paciente de 
este grupo había tomado contraceptivos orales antes de su enfermedad.

En el grupo de enfermas con hepatitis la administración de contraceptivos orales se inició dos semanas después de que las enzimas del suero, se habían hecho normales. Los contraceptivos se suministraron a todas las pacientes con ictericia obstructiva. En cuatro pacientes los contraceptivos se iniciaron ocho semanas después de la operación y en las no operadas se suministraron después de que las enzimas del suero retornaron a cifras normales. Los valores de espartato aminotransferasa (SGOT) alanino aminotrasferasa (SGPT), ornitino carbamil trasferasa, fosfatasa alcalina y bilirrubina total, se determinaron cada dos semanas durante dos meses. En algunas pacientes la SGOT y la SGPT se elevaron por encima del límite normal durante el primer mes en el cual se dieron anticonceptivos orales pero regresaron a cifras normales posteriormente. En una paciente al iniciar la medicación contraceptiva la fosfatasa alcalina era de 7.8 unidades Bessey Lowry; no obstante después de 11 semanas de tratamiento se normalizó y sólo persistieron ligeras elevaciones de SGOT y SGPT.

Se concluye que se pueden suministrar contraceptivos orales con mínimas dosis de esteroides después de desórdenes agudos hepáticos cuando los tests de función hepática han regresado a su normalidad.

\section{ANTIBIOTICOS PROFILACTICOS EN OPERACION CESAREA}

WEISSBERG, S. M., EDWARDS, N. L., \& O'LEARY, J. A. (Univ. of Miami School of Medicine, Miami, Fla. 33156). Obstet. Gynec. 38: 290-293, 1971.

Mucho se ha escrito sobre el uso profiláctico de los antibióticos. La posibilidad de que los antibióticos puedan tener valor profiláctico en infecciones desarrolladas después de la cesárea es de particular importancia en hospitales que atienden un alto porcentaje de pacientes pobres, con múltiples problemas clínicos. Para reducir la alta incidencia de morbilidad y de infecciones postoperatorias entre las pacientes indigentes y de alto riesgo a las cuales se les practicó la primera operación cesárea después de la iniciación del trabajo, se les suministraron antibióticos profilácticos a la mitad de 80 de tales pacientes. Los dos grupos fueron seleccionados dentro de pacientes negras indigentes procedentes de suburbios de una gran ciudad metropolitana. EI material clínico y las indicaciones pa- ra la operación fueron idénticas en ambos grupos. A las pacientes en estudio se les suministró penicilina cristalina, dos millones ( $\left.2^{\prime} 000.000\right)$ de unidades intravenosas cada cuatro horas, y kanamicina 500 miligramos I.M. cada 12 horas tan pronto como se decidió practicarles la cesárea. La medicación continuó durante la operación, en el postoperatorio y durante tres a cinco días. Las pacientes en el grupo control no recibieron ninguna droga.

Las pacientes que recibieron antibióticos profilácticos tuvieron un tercio 1/3 menos de complicaciones; 1/3 menos de morbilidad febril; 1/5 menos de morbilidad, y su permanencia hospitalaria fue en 3 días inferior a las que no recibieron antibióticos (5.8 días contra 8.7 días). 
Se apreció una significativa disminución en la morbilidad post-operatoria, en el número de días febriles, en el número de complicaciones, y en la duración de la estadía hospitalaria, en las pacientes en las que se utilizaron antibióticos profilácticos. No se presentaron reacciones serias o com- plicaciones causadas por las drogas.

Por lo tanto en pacientes de alto riesgo a las cuales se les practica operación cesárea después de iniciado el trabajo, consideramos útil la administración en el pre y en el postoperatorio de antibióticos profilácticos.

\section{ANALISIS DEL LIQUIDO AMNIOTICO}

JOOLS, N. D. \& JONES W. R. (Univ. de Sydney, Sydney, Australia). Minn. Med. 54: 403-408, 1971.

Cuando hay suficiente necesidad de definir la duración del embarazo más exactamente de lo que es posible usando los criterios convencionales de diagnóstico, y cuando se necesita un estimativo de la madurez funcional más que de la madurez anatómica, el análisis del líquido amniótico es una ayuda valiosa. Se examinaron noventa y una muestras de líquido amniótico obtenidas de 61 pacientes en diferentes etapas de gestación. Las muestras fueron examinadas para concentración de creatinina, para porcentaje de células escamosas feta- les coloreada con Sulfato de Azul Nilo, y para bilirrubina y pigmentos similares con espectofotometría. Los resultados de estos tres parámetros fueron combinados para producir un perfil de madurez fetal que dio una predicción más exacta que la que es posible obtener usando los parámetros individualmente. Se puede lograr una validez mayor usando análisis múltiples en serie, especialmente cuando el médico contempla la posibilidad de un nacimiento prematuro por inducción.

\section{LAS PROSTAGLANDINAS Y EL ABORTO}

ANDERSON, G. G., \& SPEROFF, L. (Yale Univ. School of Medicine, New Haven, Conn.). Clin. Obstet. Ginec. 14: 245-257, 1971.

Las prostaglandinas son un grupo de compuestos naturales recientemente descubiertos, que ofrecen un sistema nuevo y potencialmente superior para el control de la fertilidad. Los cuatro grupos principales se designan con las letras E. F. A. y B, correspondiendo a una estructura particular en anillo, mientras que el número escrito abajo indica la presencia de un doble enlace. A pesar de que las prostaglandinas originales se obtuvie- ron de vesículas seminales de ovejos, actualmente se producen sintéticamente. Los estudios iniciales sobre abortos fueron recibidos de Africa a finales de la década de los años 60. En la primera serie de pacientes se produjo el aborto en 13 de 15 con un tiempo de infusión ordinario de 12.5 horas suministrando PGF2a a una tasa constante de $50 \mathrm{ug}$. por minuto. En un estudio posterior de 52 pacientes en las cuales se usó PGE2, 
el aborto tuvo éxito en 50. En un estudio hecho en Escandinavia, después del uso de prostaglandinas en 69 mujeres, la tasa de abortos fue de más del $90 \%$ en las que tenían 8 semanas o menos de embarazo. Sin embargo, la tasa de éxitos en el segun-do trimestre fué mucho menor. Los efectos colaterales en este grupo incluyeron náuseas, vómito y diarrea. A causa de la severidad de los efectos colaterales en las próximas series de pacientes la PGE2 y la PGF2a se introdujerondi rectamente en la cavidad uterina por medio de un catéter colocado a través del cuello. Se tuvo éxito en el aborto inducido en 12 mujeres $y$ no se presentaron efectos secundarios. La experiencia del grupo africano en este momento da un total de 150 mujeres, quienes han recibido PGE2 por vía intravenosa. Se han presentado 5 fallas y el intervalo promedio de aborto es de 14.5 horas. Entre las 50 pacientes que recibieron PGF2a hubo 6 fallas y el intervalo promedio de infusión-aborto fue de 19 horas. Sobre la base de estos resultados el grupo africano ha comenzado a usar exclusivamente PGE2. En otro grupo de ensayo los mismos investigadores ensayaron una vía intravaginal usando $20 \mathrm{mg}$. sw PGE2 ○ $50 \mathrm{mg}$. de PGF2a cada dos horas en forma de supositorios; hasta ahora este método ha tenido éxito en 45 pacientes.
En un estudio realizado en Yale, se incluyeron 10 pacientes en una investigación sobre tolerancia de dosis de FGF2a usada intravenosamente, en una dosis de 25 a $200 \mathrm{~g}$ por minuto. Una paciente abortó completamente, 4 parcialmente y 5 fallaron. Debido a la naturaleza del estudio, los efectos secundarios fueron muy fuertes: náuseas, vómito y diarrea se presentaron en el $90 \%$. Además 7 mujeres tuvieron fiebre y 2 necesitaron terapia con antibióticos. Dos necesitaron transfusiones de sangre y en 5 se presentó hipertensión diastólica en algún grado. Otra paciente tuvo una aguda reacción vaso vagal, con choque general orgánico y bradicardia.

No se conoce el mecanismo de acción de las prostaglandinas para producir el aborto, pero de estudios de niveles sanguíneos periféricos de progesterona no se saca ninguna indicación de que de la gestación temprana el efecto sea sobre el "corpus luteum". Parece, más bien, ser un efecto primario de estimulación del útero. Actualmente están siendo producidas otras prostaglandinas sintéticas para ensayos clínicos por varios métodos. Además se están realizando experimentos con seres humanos y con animales en éste y en otros centros, para determinar el papel fisiológico de las prostaglandinas en la reproducción. 